\title{
Editorial
}

\section{Educar para la democracia}

${ }^{1}$ Carlos Tünnermann Bernheim

Recibido: 19 de julio de 2012/Aprobado: 23 de julio de 2012

\section{Tr} a educación para la democracia tiene que partir de una concepción clara de la misma. Temas importantes a desarrollar serían, entre otros, los siguientes: 1) la democracia como organización jurídicopolítica de la sociedad; 2) la democracia como forma de participación de los ciudadanos en la vida pública y en la elección de las autoridades; y 3) la democracia como filosofía y forma de vida, que ponga las bases de una autentica cultura democrática.

No es la intención que los alumnos de primaria y secundaria se transformen en expertos constitucionalistas, tarea propia de las Facultades de Derecho. De lo que se trata es de que tomen conciencia sobre la importancia de la Constitución Política como ley suprema del país, a la que deben supeditarse todo el ordenamiento jurídico y las autoridades, y como norma que define los derechos y deberes individuales, políticos, económicos y sociales de los habitantes y ciudadanos; organiza los poderes del Estado y determina el límite de sus atribuciones.

El artículo 117 de nuestra Constitución Política establece que el estudio de la Constitución debe ser promovido por el Estado. Existe también la Ley de Promoción de los Derechos Humanos y de la Enseñanza de la Constitución Política, aprobada en septiembre de 1995, que declara el primer día de septiembre como día de la Constitución Política y su estudio, junto con los Derechos Humanos, como materias obligatorias en todos los niveles del sistema educativo.

En lo que respecta a los Derechos Humanos, no basta el conocimiento de la parte declarativa o dogmática de la Constitución. Es preciso también conocer los textos de las grandes declaraciones internacionales referentes a los derechos humanos, como la Declaración Universal y la Convención Americana, que entre nosotros tienen el carácter de leyes de la República por mandato constitucional (Arto. $46 \mathrm{Cn}$ ).

Como parte medular de este proceso educativo es necesario inculcar a los educandos el amor a la patria, a sus símbolos, y el orgullo de ser nicaragüense. Estimular en los estudiantes la valoración de la identidad nacional. Valga aquí lo que Renán consideraba como los elementos constitutivos de una nación: "Una nación requiere de glorias comunes en el pasado, una voluntad común en el presente; haber hecho grandes cosas juntos y querer seguir haciéndolas todavía".

La educación para la democracia no se concibe como una asignatura más añadida al pensum escolar. Ella debe partir de una concepción integral e impregnar todo el proceso educativo. Debe ser inspiradora, polinizadora. Cada centro educativo debe ser un lugar de aprendizaje democrático y de práctica de la democracia por las relaciones democráticas que deben darse entre todos sus componentes. En este proceso, la función del maestro será orientar, guiar el aprendizaje de las conductas y la adopción de valores que conduzcan al educando a construir su autonomía de juicio en la participación política. Una manera de hacer del aula una vivencia democrática y un ejercicio de ciudadanía, es estableciendo los gobiernos estudiantiles, de suerte que los estudiantes participen en la administración del aula escolar y de su escuela, mediante un gobierno estudiantil libre y democráticamente electo.

1 Jurista, educador y escritor. 
En conclusión, educar para la democracia es proporcionar los conocimientos básicos que nos permitan saber a qué nos estamos refiriendo cuando hablamos de democracia, a fin de que los educandos comprendan el origen, evolución y naturaleza de la democracia. Thomas Jefferson consideraba que el estudio de la historia es "el tema principal en la educación para la democracia". La historia nos permite comprender lo que es realmente la democracia y cuando ella se eclipsa y las razones de tal eclipse. Al reflexionar sobre la historia de Nicaragua, José Coronel Urtecho llegó a la conclusión que el hilo conductor de nuestra historia ha sido una sucesión de guerras civiles, después de las cuales, en lugar de instaurar un régimen democrático, volvemos a caer en el caudillismo y la dictadura. Recordemos la frase de Santayana: "Los pueblos que ignoran su historia, están condenados a repetirla".

Los procesos educativos tienen por misión suscitar en las personas los aprendizajes que le permitan participar activamente, durante toda su vida, en un proyecto social, en un proyecto de nación. Y la escuela es, sin duda, un agente privilegiado en la adquisición de los principios y prácticas democráticas que preparen para una participación responsable, crítica y constructiva en ese proyecto.

Managua, Agosto de 2012.

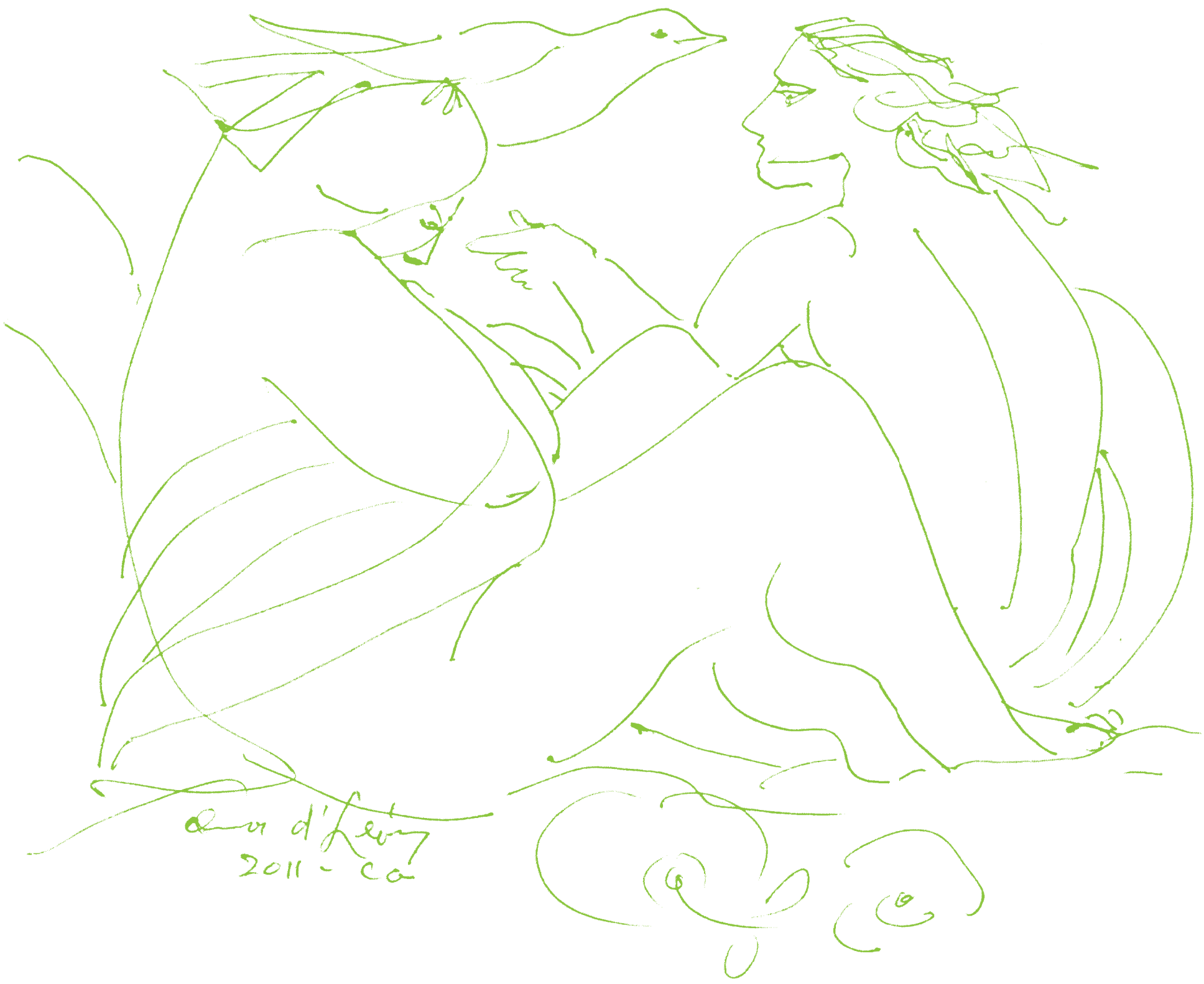

